\title{
Problems in Developing an Alternative to the TOEFL ${ }^{1}$
}

Margaret Des Brisay

An increasing number of programs and institutions have developed tests of English for academic purposes to be used in making admissions decisions at North American universities. It is not unreasonable for admissions officers to request information that will enable them to compare scores from a new and unfamiliar test with scores from the tests they have traditionally used. It is important, however, that the right questions be asked, and this is not always the case. What admissions officers frequently want is a conversion table calibrating scores from different tests, whereas the real question is not how well do two tests measure each other but how well does each test measure the construct of interest. Nevertheless, test scores are used as a basis for action, and it is important to provide decision makers with information that has applied utility until such time as satisfactory experience with the new test establishes its credibility. This article specifies a methodology for data collection, and compares appropriate statistical methods for data analysis including estimates of decision consistency, decision agreement, and shared construct relevant variance. The studies on which this article is based involved four groups of examinees (totalling 250) who wrote both the Test of English as a Foreign Language (TOEFL) and the Canadian Test of English for Scholars and Trainees (CanTEST).

An increasing number of Canadian postsecondary institutions have developed ESL proficiency tests designed to measure the language abilities demanded in an academic program (Des Brisay, Elson, Fox, \& Ready, 1991). These testing initiatives have been motivated by a need for tests that are aligned with specific curricula, for tests that provide the diagnostic information required in program planning, for tests that provide the information necessary for program evaluation, or simply for tests that can be scheduled to meet administrative needs. In many cases it would be useful if scores from such tests could be used for admissions purposes in place of scores from such widely available international tests as the Test of English as a Foreign Language (TOEFL) or the International English Language Testing Service (IELTS). Otherwise, students may have to be tested twice, once to get the desired information and once to meet the requirements of a university admissions office. It follows, then, that test developers must be prepared to supply evidence supporting the use of scores from their tests for admissions purposes. 
This article reports on some of the research activities undertaken by the developers of the Canadian Test of English for Scholars and Trainees (CanTEST) in order to establish the CanTEST as a valid ESL admissions test. The CanTEST is a bank of subtests from which versions are compiled to meet program needs. Much of the bank was originally developed and validated at the University of Ottawa for use in human resources development programs funded by the Canadian International Development Agency (CIDA). In order for the CanTEST to be of maximum use as a selection instrument in these programs it was necessary to have some assurance that scores would be accepted for university admissions purposes. CanTEST developers quickly learned that the evidence score users invariably wanted before giving such assurance concerned the comparability of scores from this new and unfamiliar test with those from whichever test they had traditionally used.

\section{How should test developers respond to this request for comparable scores?}

Language testers recognize that information linking scores from two different tests is only one kind of evidence that can be presented to establish the credibility of a new test. Far more compelling evidence could be assembled by examining the quality of the new test: its relevance to the target situation, the criteria used for content and task selection, the reliability of its scores across administrations, the process by which standards were set, and less theoretical issues such as its security and accessibility. After all, the real question is not how well do two tests measure each other. Rather it is how well does a particular test measure the construct of interest which is the language proficiency needed for successful performance in an academic environment. Until such time as this view is shared by score users in general, however, some effort to link different ESL assessments in terms of their scores, and the decisions based on their scores, may have to be made. Reluctance to do so will simply confirm the use of a single test or a narrow range of tests in admission procedures, thereby weakening the motivation for many valuable testing initiatives and making it difficult to meet the information requirements of program planners and sponsoring agencies.

What would be the ideal evidence?

No doubt the most compelling evidence supporting the inferences to be made from a test score would be evidence that the score reliably predicted the criterial behavior, in this case academic success, perhaps as measured by first semester marks or supervisors' reports. Unfortunately, predictive validity studies (Hale, Stansfield, \& Duran, 1984; Black, 1991) have overall failed to show any clear relationship between language proficiency and academic success. The problems associated with such studies are summarized in Graham (1987) and relate to (a) the criterion for judging academic 
success, (b) limitations in the measures of English proficiency used, (c) the interpretation of any relationships found, and (d) the large number of uncontrolled variables involved in academic success. An adequate level of ESL proficiency reliably measured is no guarantee of academic success. After all, even native speakers can and do fail. The language demands of the program, the standards of the university, a student's expertise in his or her discipline, and the patience of a particular supervisor can be equally important factors in predicting student success. Graham concludes that, at best, an ESL admissions test can identify students who are not likely to be handicapped in any serious way by their level of English language proficiency.

Predictive validity studies are further complicated by the fact that applicants who do not have the required score are not admitted, and so the range of language abilities among those who are admitted is very restricted. Moreover, we do not know how many of the rejected applicants might well have performed successfully had they been admitted. Ideally, the first step in a proper study would involve administering the test but ignoring the results when making admissions decisions, an idea unlikely to appeal to many university admissions committees. And if the gathering of evidence for the predictive power of any one test has proven problematic, it is hard to imagine how a comparability study with academic success as the criterion measure could be designed and interpreted.

How should the data for linking scores be collected?

If two disparate ESL assessments are to be usefully compared on the basis of scores and/or the decisions based on those scores, there are certain constraints on data collection. First of all, it must be arranged for examinees to write both tests within one or two weeks with little or no intervening language training. It would make no sense to compare scores from tests written six months apart. The examinees may have made no use of their English in the intervening period, in which case the score on the second test could be lower due to attrition; or they may have been in intensive language training for much of the interval, in which case only their score on the second test would reflect the impact of this training. Second, every effort must be made to replicate operational testing conditions for both tests. Ideally, examinees should feel that decisions affecting their futures will be made on the results of either of the two tests. If only one of the tests carries high-stakes while the other is being used experimentally, test performance will be differentially affected. Although some students will experience less test anxiety on the experimental test and hence perform better, experience shows that most will put more effort into performing well on the official test. (This would be true in the case of a high-stakes and low-stakes administration of the same test). Third, efforts must be made to ensure that test preparation activities have not left examinees more familiar with the method and format of one of the tests 
than with those of the other. If this is not done, the effect of this preparation must be quantified in some way so that it can be taken into consideration when making the comparison.

Unfortunately, these conditions are difficult to satisfy in real life where research must be done with naturally occurring groups that may have been formed for the express purpose of preparing students for one of the two tests. Moreover, if the data are collected in instructional settings, again the full range of scores will not be represented: weak candidates may not have been eligible for advanced language training and proficient ones will have been exempted. And unless the comparability study is collaborative, item level statistics will be available for only one of the tests, thus limiting the correlational studies that can be done. Where satisfactory data cannot be collected, inferences about the comparability of two sets of scores must be interpreted with considerable caution. To attempt, as is sometimes done, to construct a conversion table based on self-reported test scores obtained at different times on different versions of an alternate test is both useless and misleading.

\section{Suppose these data are just not available?}

Given the difficulty of collecting and interpreting evidence of value in linking scores from two different ESL assessments, it is not surprising that many practitioners refuse to play the game and insist that each test be evaluated independently. Of course, not all comparissons require administering both tests to the same examinees under the strict conditions described above. For example, the user's manual for the International English Language Testing Service (IELTS) simply states that institutions that accept a certain score on the IELTS also accept a corresponding score on the Test of English as a Foreign Language (TOEFL). This is an honest statement about the administrative policy of British postsecondary institutions, and one assumes that it is based on the experience of the reporting institutions with the two tests and with the testing services that produce them. This may be the best solution but, unfortunately, not one that is available to those who are trying to win acceptance for a new and unfamiliar test.

Alternatively, a test developer can present score users with the percentile rankings for different scores and invite comparisons with the percentile rankings of scores from another test if these are available, as they are in the case of the TOEFL. However, no assurance can be given that examinees were drawn from the same population. In the case of an in-house admissions tests, for example, only those examinees who have failed the test normally used for admissions purposes at that institution may be required to write, whereas at overseas testing sites the full range of abilities is likely to be represented. Tables such as Table 1, which shows percentile ranks for scores on the Canadian Test of English for Scholars and Trainees (CanTEST), are useful in that they give some indication of the relative difficulty of a test for its 
population. A score user might well wonder about a test that everybody passed or failed. If the situation is one in which two different placement instruments intended for in-house use are being investigated, percentile ranks may provide adequate information for linking the two tests. If the situation is one in which highly consequential decisions are being made, score users must exercise considerable caution in using such tables to predict scores for individual examinees.

What methods exist for linking scores from different tests?

Mislevy (1992) describes five methods for linking educational assessments: equating, calibration, projection, statistical moderation, and social moderation. The extent to which two tests measure the same thing in the same way and with the same accuracy will determine the appropriate method. The more the assessments differ in form, content, and context of use, the less confidence we can have in the evidential value of data from one test for the other.

Equating and calibration demand a strong association between two assessments. Several different procedures exist for equating the scores from two tests (Angoff, 1984; Holland \& Rubin, 1982), but these procedures are to be used with different forms of the same tests, written to the same set of specifications, with similar formats and statistical properties. Most equating procedures make the assumption of equity; that is, they assume that it should make no difference to examinees which test they write and that the equating formula can be used to equate Form A to Form B or Form B to Form A. The purpose of equating in such cases is to make adjustments for the inevitable minor differences in difficulty between the two versions. Calibration, for Mislevy (1992), differs from equating in that the two assessments are not linked directly to each other but to a common frame of reference. One test may be a shorter version of the other or designed to give maximum informa-

Table 1

Minimum Percentile Ranks for CanTEST Band Scores*

\begin{tabular}{lccc}
\hline & Listening & Reading & Writing \\
\hline Band 5.0 & 88 & 89 & 93 \\
Band 4.5 & 76.4 & 79.5 & 84 \\
Band 4.0 & 62.7 & 59.8 & 63 \\
Band 3.5 & 39.7 & 41 & 36 \\
\hline
\end{tabular}

* Based on total group of examinees tested from August 1987 through to January 1992 ( $n=3,181)$, test population predominantly Chinese. 
tion at a different point in the ability continuum, but both versions are compiled from the same bank of items and can be referenced to the same scale.

Methods that are at least feasible for relating scores from two different ESL proficiency tests fall into the categories of projection and moderation (both statistical and social). For Mislevy (1992), projection evaluates the evidence that outcomes from one assessment provide about likely outcomes on another, whereas moderation simply aligns scores from the two as to some measure of comparable worth. In linking disparate assessments through projection or moderation, the intention is not to provide equivalent scores, but comparable scores in the sense of scores that are of comparable value in a given context for a given purpose. In cases where both tests can be administered to the same group of examinees, some of the statistical techniques may be similar to those of equating, but results must be used to make very different inferences. After all, one is adjusting for a good deal more than minor differences in difficulty. Even though the two tests are being used for the same purpose, and are constructed around the same conception of competence, they will have different formats and test different samples of language behavior. To use the results to produce a conversion table in a high-stakes setting would be unethical to say the least, given the danger that such tables may be used to make decisions about individual students.

What can the small-scale test developer do?

The section that follows reports on some of the efforts made by the developers of the Canadian Test of English for Scholars and Trainees (CanTEST) to satisfy the information requirements of admissions officers at a number of Canadian universities. Research was done in contexts where only TOEFL (scaled) scores were available for comparison purposes. The CanTEST measures all four skills, but because the TOEFL does not routinely provide direct measures of speaking and writing, only CanTEST listening and reading comprehension scores were used in the comparisons.

One common way of estimating the relationship between two sets of scores is to compute the raw correlation. The square of this correlation is a rough measure of the shared variance of the two tests. One would expect a fairly strong correlation between two tests designed to assess English language proficiency, and this has in fact been the case in all of the CanTESTTOEFL correlational studies conducted (Des Brisay, 1988). Table 2 shows the correlations obtained between pairs of these tests on several occasions in the context of an overseas predeparture ESL program in Indonesia. Subjects were 52 Indonesians who wrote official versions of the CanTEST and the TOEFL with the understanding that success on either one of the tests would qualify them for a Canadian assignment. At Time One, the correlation between the two tests was .74, and at Time Two, following 18 weeks of inten- 
Table 2

Intercorrelations Among Test Totals $(\mathrm{N}=52)$

\begin{tabular}{lllll}
\hline Test & 1 & 2 & 3 & 4 \\
\hline 1. CanTEST (Time 1) & - & & & \\
2. TOEFL (Time 1) & .74 & - & & \\
3. CanTEST (Time 2) & .85 & .84 & - & \\
4. TOEFL International (Time 2) & .84 & .76 & .77 & - \\
5. TOEFL Institutional (Time 2) & .71 & .71 & .71 & .76 \\
\hline
\end{tabular}

sive language training, the correlation was .77. These coefficients can be compared with that of .73 obtained between two versions of the TOEFL, albeit one of them an institutional version (see remarks above). The other correlations, though stronger in some cases, are confounded by the effects of intervening language instruction.

One problem in the interpretation of these correlations is the lack of a benchmark for judging their strength. University registrars might like them to be as high as possible, taking this as evidence that the two tests are doing the same thing. Test developers who believe their tests to be a more valid measure might prefer a more modest correlation as evidence of substantial differences between the tests in either the trait measured or the method used to measure it. Furthermore, the usual caveats in interpreting correlations must kept in mind. For example, if the subjects are homogeneous in their ESL proficiency, there will be less variance in the scores and correlations will be lower.

Correlations enable comparisons to be made of the overall ranking of examinees on any pair of tests. Far more relevant to the various stakeholders, however, is a comparison of the decisions made on the basis of test results. Evidence for making this comparison can be presented in the form of cross tabulations of scores as shown in Table 3. These data were obtained from the same sample of examinees as shown in Table 2. Table 3 gives an honest picture of the relationship between the two sets of scores for a given group of examinees, and if the results were replicated in several studies some rough estimates of score linkage could be made by means of projection. However, the information in Table 3 may be too detailed to be easily assimilated, and there is danger that score users will focus on the individual exceptions (which tend to cluster around the cut score) and fail to appreciate group tendencies.

The information in a cross tabulation of scores can be summarized in a 2 by 2 contingency table as shown in Figure 1. In Figure 1(a) it can be seen that 
Table 3

Cross Tabulation of TOEFL Score by CanTEST Band Score Canada Indonesia Language Program $(\mathrm{N}=51)$

\begin{tabular}{|c|c|c|c|c|c|c|c|}
\hline \multicolumn{8}{|c|}{ CanTEST Bands } \\
\hline & 3.50 & 3.75 & 4.0 & 4.25 & 4.50 & 4.75 & 5.0 \\
\hline क $\quad-469$ & 1 & & & & & & \\
\hline$\approx 490-509$ & 1 & 1 & 1 & & 2 & & \\
\hline O $510-529$ & & 1 & 3 & 5 & 4 & 1 & \\
\hline $530-549$ & & & 1 & 3 & 4 & 4 & \\
\hline$-550-569$ & & & & 3 & 1 & 5 & 3 \\
\hline 눈 $570-589$ & & & & & & 1 & 3 \\
\hline$\stackrel{\circ}{\vdash} 590-609$ & & & & & & 1 & 2 \\
\hline Chi-Square & & Value & & $D F$ & & Significance & \\
\hline Pearson & & 71.0 & & 36 & & .0003 & \\
\hline Cramer's V & & .484 & & & & .0003 & \\
\hline
\end{tabular}

identical pass-fail decisions were made in the case of 44 of the 52 examinees. Thus the decision agreement in this example would be $84.6 \%{ }^{1}$

Additional examples of decision agreement are displayed in Figure 1 (b) and (c). Less decision agreement was obtained, as might be expected, in the two studies where only one test was administered in a high-stakes setting. It should be noted that it is always be possible to obtain perfect agreement with respect to success by raising the cut score for one of the tests. If the decision agreement, more properly termed decision consistency, between two versions of the same test is available for comparison, it may help to put things in perspective. Figure 1(d) shows that the decision consistency with respect to pass-fail between the February and March 1993 International TOEFL for a group of 32 Indonesians was $72 \%$.

Statistically minded readers will know that a range of possible scores on Test $Y$ can be predicted from observed scores on Test $X$ if sufficient data are available using, for example, the SAS regression program to generate multiple predictor equations with a $95 \%$ confidence interval for the predicted scores. It is unlikely that any small-scale developer could obtain appropriate data from a large enough sample to make comparisons of this sort practical. 
TOEFL

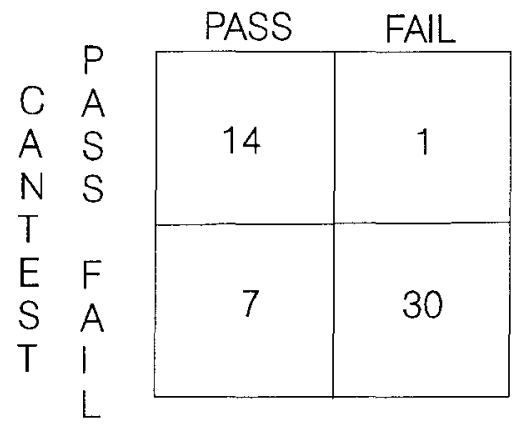

Decision Agreement $=85 \%$

\section{$\mathrm{N}=53$}

High Stakes: CanTEST yes TOEFL yes

TOEFL Cut Score $=550$

CanTEST Cut Score $=$ Band 4.5

Figure 1a. Contingency Table for CIPP (Jakarta).

\section{TOEFL}

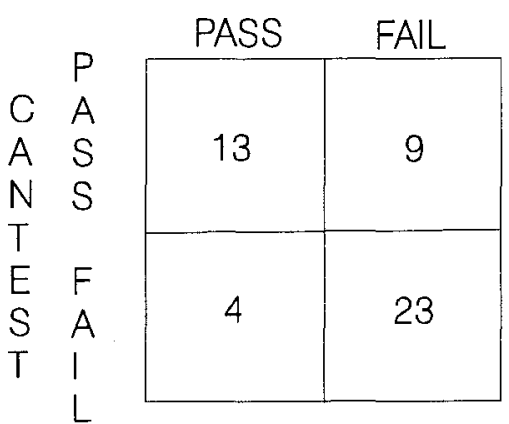

Decision Agreement $=74 \%$

$\mathrm{N}=49$

High Stakes CanTEST yes TOEFL no

TOEFL Cut Score $=510$

CanTEST Cut Score $=4.0$

Figure 1c. Contingency Table for CCLC (Beijing).
TOEFL

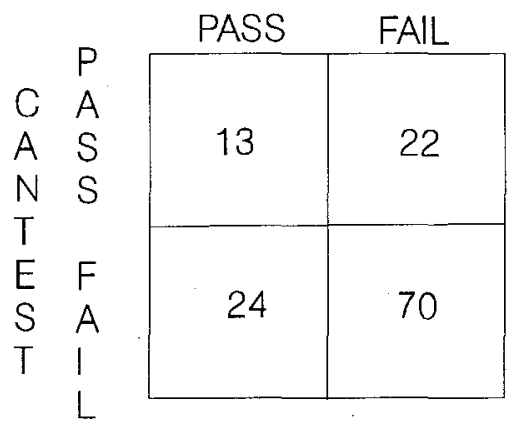

Decision Agreement $=64 \%$

$N=129$

High Stakes: CanTEST no TOEFL yes

TOEFL Cut Score $=550$

CanTEST Cut Score $=$ Band 4.5

Figure 1b. Contingency Table for Overseas Training Office (Jakarta).

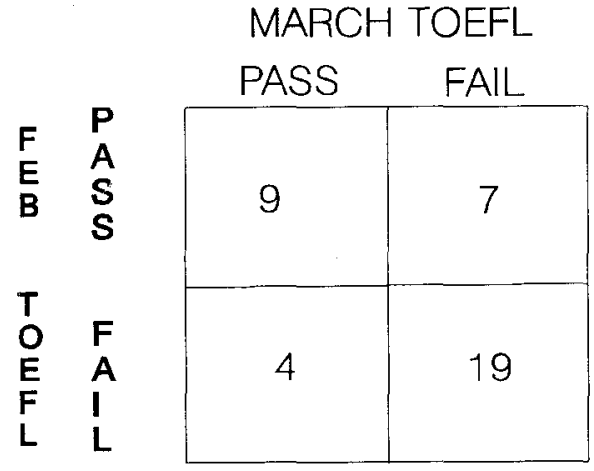

Decision Consistency $=72 \%$

$\mathrm{N}=39$

High Stakes: February yes March yes

TOEFL Cut Score $=550$

Figure 1d. Contingency Table for February-March'93 TOEFL. 
So what do you offer the admissions officer who asks for a conversion table?

Admissions officers must be persuaded to live with less certainty. After all, they routinely accept as comparable grades from different high schools known to have different standards, or grades from foreign universities about which little or nothing is known. But score users are anxious to appear fair, and what could appear fairer than to insist that everyone produce scores from the same test if that is possible? It is usually not feasible to take all the relevant factors into consideration when making admission decisions and as long as the available places are filled with qualified candidates, universities may prefer not to worry about whether they were in every case filled with the most qualified candidates. The burden of proof, then, falls on test developers who are trying to establish the credibility of a new test. They must be prepared to provide as much information as they can in the early stages of test use and this will, of necessity, include information linking scores in some principled way.

We have seen how scores from different tests may be usefully compared by means of rank correlations, cross tabulations, and contingency tables. Comparisons of this sort have the advantage that they are easy to estimate and require only scores, not item responses. However, results will vary over time or with the group of examinees from whom the test data were obtained and must always be interpreted in the light of other available informationinformation about test preparation activities, for example. It must be kept in mind that:

- no single study can provide the information needed to link scores from different tests;

- more importantly, the results of such studies should not be used to predict scores for individual examinees, especially in high-stakes settings.

It is never possible to say with perfect confidence that an individual with score $X$ on test $X$ will have score $Y$ on test $Y$. After all, even in the case of rigorously equated tests, there is always the standard error of measurement to be contended with.

Finally, it must be accepted that when any test is used to make pass-fail (master-nonmaster) decisions, a certain number of borderline examinees will be misclassified. There will be false positives, examinees who achieve the required test score but did not really possess an adequate level of ESL proficiency, and false negatives, those who do not achieve the required score but are in fact sufficiently proficient. One can always limit the number of false positives by raising the "passing" mark, but in doing so one will increase the number of false negatives and, in the case of ESL admissions tests, deny admission to students who might have performed satisfactorily had they been admitted. Not all score users are aware of this potential for 
misclassification, and it is up to test developers to give the warning. In the end, however, score users themselves must decide which type of error they can most comfortably accept.

Notes

${ }^{1}$ This article is a revised version of a paper presented at the 15th Annual Language Testing Research Colloquium, Cambridge and Arnhem, in August 1993.

${ }^{2}$ The use of Subkoviak's kappa to account for chance agreement would not be appropriate here since that would be to assume that one of the measures was the "true" or criterion one.

The Author

Margaret Des Brisay is a member of the teaching staff at the Second Language Institute, University of Ottawa. For the past eight years, she has served as director of the CanTEST project, developing tests of ESL and FLS for use in measuring the language proficiency of international candidates for academic and professional assignments in Canada. Her research interests focus on language testing and she has presented and published frequently in this field.

\section{References}

Angoff, W.H. (1984). Scales, norms and equivalent scores. Princeton, NJ: Educational Testing Service.

Black, J. (1991). Performance in English skills courses and overall academic achievement. TESL Canada Journal, 9(1), 42-55.

Des Brisay, M. (1988). Final report on test procedures used in the Canada Indonesia Predeparture Program. Ottawa: World University Service Canada.

Des Brisay, M., Elson, N., Fox, J., \& Ready, D. (1991). Testing for academic readiness. In Make changes, make a difference. Conference proceedings of the TESL Ontario' 91 Conference.

Graham, J.G. (1987). English language proficiency and the prediction of academic success. TESOL Quarterly, 21(3), 505-522.

Hale, G.A., Stansfield, C.W., \& Duran, R.P. (1984). Summaries of studies involving the Test of English as a Foreign Language, 1963-1982. Princeton, NJ: Educational Testing Service.

Holland P.W., \& Rubin, D.B. (Eds.). (1982). Test equating. New York: Academic Press

Mislevy, R.J. (1992). Linking educational assessments: Concepts, issues, methods and prospects. Princeton, NJ: Educational Testing Service. 